\title{
An intervention study to enhance AIDS awareness among underprivileged population in Chandigarh
}

\author{
Vikas Bhatia, H. M. Swami, Amrit Pal Kaur \\ Department of Community Medicine, Government Medical College, Chandigarh, India.
}

Address for correspondence: Dr. Vikas Bhatia, Sr. Lecturer, Department of Community Medicine, Government Medical College, College Building, Sector 32-A, Chandigarh - 160047, India. E-mail: drbhatiav@yahoo.com

\begin{abstract}
Background: It is estimated that 4 million persons are suffering from HIV infection/AIDS in India. A family health awareness campaign (FHAC) has been implemented under the National AIDS Control Programme (NACP) to scale up HIV/AIDS awareness in vulnerable groups. Methods: A community based study was conducted in April 2001 to find the impact of FHAC and IEC activities in 12 villages and slums with a population of 1-1.5 lakhs in Chandigarh. Information was collected from 643 persons in the age group of 15-49 years, 323 in the pre-intervention phase and 320 in the post-intervention phase. Results: Awareness about AIDS increased from $58.2 \%$ to $70 \%(p<0.01)$. The major sources of information were the mass media and friends. Knowledge regarding the mode of spread also increased after the campaign. Knowledge regarding prevention of AIDS by using condoms increased from $42 \%$ to $61.2 \%$; having a single partner, from $59 \%$ to $72.3 \%$; using safe blood, from $14.9 \%$ to $29 \%$; and sterile needles/syringes, from $18.1 \%$ to $33.9 \%$. Over $90 \%$ of respondents consider AIDS a dangerous disease. Conclusion: Community based intervention such as FHAC and IEC activities were successful in enhancing the awareness among underprivileged groups. Since a large section of the population still remained unaware, regular efforts must be made to achieve universal awareness about AIDS.
\end{abstract}

KEY Words: AIDS, Awareness, Intervention, IEC

\section{INTRODUCTION}

AIDS is considered a dreaded disease as no effective vaccine or drug therapy is available. According to recent estimates, 42 million people suffer from HIV/AIDS, with 5 million people newly infected with HIV and 3.1 million deaths in the year 2002 globally. ${ }^{1}$ Since the detection of the first case in India in 1986 in Tamil Nadu, 68809 confirmed cases of AIDS have been reported till February, 2003. ${ }^{2}$

Mass media campaigns and interpersonal communication by non-government organization (NGO's) have succeeded in raising the level of awareness about AIDS in the general population in urban areas. Therefore, Government of India launched an intensive programme to create awareness about AIDS and to provide services for sexually transmitted diseases (STDs) and reproductive tract infections (RTIs) through family awareness campaigns. ${ }^{3}$ The present study was conducted in the community to find the change in the level of awareness about AIDS occurring as a result of intervention in the form of camps, awareness campaigns and IEC activities in a rural and slum

\footnotetext{
How to cite this article: Bhatia V, Swami HM, Kaur AP. An intervention study to enhance AIDS awareness among underprivileged population in Chandigarh. Indian J Dermatol Venereol Leprol 2004;70:87-91.

Received: March, 2003. Accepted: February, 2004. Source of Support: Nil.
} 
population in Chandigarh.

\section{METHODS}

The Union territory of Chandigarh has a population of 0.9 million in an area of $114 \mathrm{sq} \mathrm{km}$. It has attracted not only a large number of youths for educational purposes but also a large population of migrants from the states of Uttar Pradesh and Bihar, resulting in the development of 27 slums. The rural area of Chandigarh comprises of 26 villages that are in close proximity to the city. Thus, nearly $50-55 \%$ of the population of Chandigarh is in urban sectors, $10 \%$ in rural areas and $35-40 \%$ in slums and resettled colonies.

In April-May, 1999, the Government of India initiated a family health awareness campaign under the National AIDS Control Programme which was implemented in Chandigarh. Increasing the awareness of HIV/AIDS in rural areas and in other vulnerable groups of the population, and identifying high risk groups for a targeted intervention programme were among its objectives.

Our study was conducted in April 2001 when a similar campaign was implemented by the State AIDS Control Society in collaboration with various NGO's. Pre-camp activities were carried out in 12 village and urban slums where ICDS workers (Anganwadi workers) made house to house visits over 4 days and distributed information cards besides educating and informing the community about AIDS. Subsequently camps were organized in the respective villages for people in the age group of 15-49 years. Symptoms related to STD's were detected and treated and IEC activities in the form of talks, dance and drama, folk dances, posters/handbills were carried out. One such camp was organized daily from 16-30th April in the selected villages and slums.
A team from the Department of Community Medicine collected information in a standard format on HIV/AIDS from people in the age group of 15-49 years in these villages and slums. The information was collected from 4 village and 6 slums where 30-40 persons each were contacted randomly so as to represent all areas. The team visited the areas to collect the baseline data prior to implementation of FHAC related activities, and once again one week after the camp was over. Thus, 323 persons were enrolled in the study in the preintervention phase and 320 in the post-intervention phase.

\section{RESULTS}

The present study was conducted in 10 villages and slums with a population of about 1-1.5 lakhs which generally comprised of the low socioeconomic and underprivileged strata of society. The majority of the population consisted of daily wagers, small shopkeepers and unskilled laborers.

The overall AIDS awareness increased from $58.2 \%$ in the pre-intervention phase to $70 \%$ (statistically significant, $p<0.01$ ), the increase being lower in males than in females, where it increased from $46.5 \%$ to $64.8 \%$ (Table 1). However, more males were aware of AIDS in the pre- and post-intervention phases. The rural population was more aware in both the phases. The awareness level increased from $70 \%$ to $77.4 \%$ in the rural population and from $51 \%$ to $64.5 \%$ in the slum population. The major source of information about AIDS was the mass media, followed by friends and camps, in both phases (Table 2).

The increase in awareness levels about the modes of transmission was good regarding blood transfusion (from 22.8\% to 46\%) and unhygienic needles/syringes

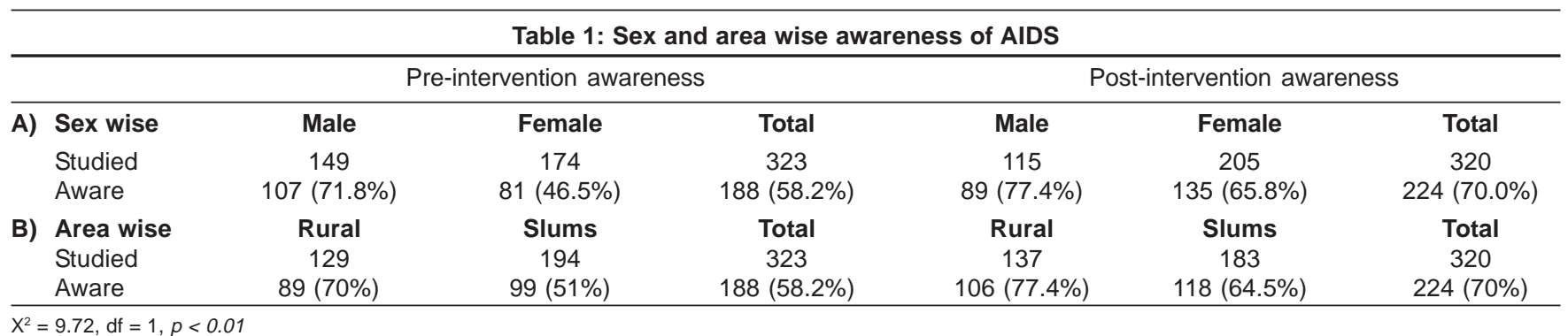




\begin{tabular}{lcc}
\hline \multicolumn{2}{c}{ Table 2: Sources of information about AIDS } \\
\hline Source of information & $\begin{array}{c}\text { Pre-intervention } \\
\text { awareness }(\mathrm{n}=188)\end{array}$ & $\begin{array}{c}\text { Post-intervention } \\
\text { awareness }(\mathrm{n}=224)\end{array}$ \\
\hline Friends & $64(25.3)$ & $61(27.2)$ \\
Relatives & $4(1.6)$ & $16(7.1)$ \\
Camps & $26(10.3)$ & $45(20.0)$ \\
Health workers & $25(9.9)$ & $32(14.2)$ \\
Mass media & $124(49.2)$ & $187(83.4)$ \\
\hline
\end{tabular}

Figures in parenthesis indicate percentage

(from $35.6 \%$ to $51.8 \%$ ), but was low regarding mother to child transmission (from $10 \%$ to $17 \%$ ) (Table 3 ). Awareness regarding multiple sex partners remained high at around $70 \%$ in both phases. The major gain was noticed in males regarding blood transfusion and in females regarding unhygienic syringes and needles.

After the intervention the overall awareness about prevention of AIDS improved (Tables 3-4). More persons knew about condoms (from $42 \%$ to $61.2 \%$ ), having sex with a single partner (from 59\% to $72.3 \%$ ), using safe blood (from $14.9 \%$ to $29 \%$ ) and sterile needles and syringes (from $18.1 \%$ to $33.9 \%$ ). Over $90 \%$ of the participants considered AIDS a dangerous disease (Table $5)$, most commonly (57.3\%) because no treatment is available, because there is no vaccine $(20.1 \%)$ or because patients die within a few years $(26.9 \%)$, according to the post-camp evaluation study.

\section{DISCUSSION}

Target specific intervention programmes are important strategies of the National AIDS Control Programme in India. The present study was conducted as a part of a family health awareness campaign. Its results reflect the effect of the intervention carried out by a large number of health workers, ICDS workers who were supported by doctors, technician, health managers, etc. It was heartening to note that the baseline AIDS awareness in the community was $58 \%$, over two-thirds among males and a little below 50\% among females. But extensive IEC activities and camps resulted in an increase to a level of $70 \%$.

The rural population was more aware of AIDS than slum dwellers possibly because of the floating nature of the migrant population and the low literacy and nonexistent or poor health services in slum areas. But FHAC resulted in a considerable increase in the awareness among the slum population (from $51 \%$ to $64 \%$ ) in comparison to the rural community (from $70 \%$ to $77.4 \%$ ). In a similar study, $68 \%$ of the persons were aware of HIV/AIDS in 1999 as against 49\% in $1996 .{ }^{4}$ Thus, FHAC is an effective means to enhance AIDS awareness among the poor. In Kargil a community based survey in the reproductive age group population reported that only one-fifth were aware of AIDS; this was probably due to reasons like the orthodox population, low female literacy, low sex ratio and issues related to sexuality being taboo. ${ }^{5}$

Table 3: Modes of spread of AIDS

\begin{tabular}{|c|c|c|c|c|c|c|}
\hline \multirow[t]{2}{*}{ Mode of spread } & \multicolumn{3}{|c|}{ Pre-intervention awareness } & \multicolumn{3}{|c|}{ Post-intervention awareness } \\
\hline & $\begin{array}{c}\text { Male } \\
(n=107)\end{array}$ & $\begin{array}{l}\text { Female } \\
(\mathrm{n}=81)\end{array}$ & $\begin{array}{c}\text { Total } \\
(\mathrm{n}=188)\end{array}$ & $\begin{array}{c}\text { Male } \\
(\mathrm{n}=89)\end{array}$ & $\begin{array}{l}\text { Female } \\
(n=135)\end{array}$ & $\begin{array}{c}\text { Total } \\
(\mathrm{n}=224)\end{array}$ \\
\hline Bad blood transfusion & $23(21.4)$ & $20(24.6)$ & $43(22.8)$ & $61(68.5)$ & $42(31.1)$ & $103(46.0)$ \\
\hline Unhygienic syringes and needles & $43(40.0)$ & $24(29.6)$ & $67(35.6)$ & $59(66.3)$ & $57(42.2)$ & $116(51.8)$ \\
\hline Mother to child transmission & $10(9.3)$ & $11(13.5)$ & $19(10.0)$ & $20(22.5)$ & $18(13.3)$ & $38(17.0)$ \\
\hline Multiple sex partners & $78(72.8)$ & $54(66.6)$ & $132(70.2)$ & $56(62.9)$ & $110(81.5)$ & $166(74.1)$ \\
\hline
\end{tabular}

Figures in parenthesis indicate percentages

Table 4: Awareness regarding prevention of AIDS

\begin{tabular}{|c|c|c|c|c|c|c|}
\hline \multirow[t]{2}{*}{ Prevention of AIDS } & \multicolumn{3}{|c|}{ Pre-intervention awareness } & \multicolumn{3}{|c|}{ Post-intervention awareness } \\
\hline & $\begin{array}{c}\text { Male } \\
(n=107)\end{array}$ & $\begin{array}{l}\text { Female } \\
(\mathrm{n}=81)\end{array}$ & $\begin{array}{c}\text { Total } \\
(\mathrm{n}=188)\end{array}$ & $\begin{array}{c}\text { Male } \\
(\mathrm{n}=89)\end{array}$ & $\begin{array}{l}\text { Female } \\
(n=135)\end{array}$ & $\begin{array}{c}\text { Total } \\
(n=224)\end{array}$ \\
\hline Hygiene & $4(3.7)$ & $2(2.5)$ & $6(3.2)$ & $36(40.4)$ & $23(17.0)$ & $59(26.3)$ \\
\hline Using condom & $51(47.7)$ & $28(34.6)$ & $79(42.0)$ & $71(79.8)$ & $66(48.9)$ & $137(61.2)$ \\
\hline Single partner & $69(64.5)$ & $42(51.8)$ & $111(59.0)$ & $55(61.8)$ & $107(79.2)$ & $162(72.3)$ \\
\hline Safe blood & $17(15.9)$ & $11(13.6)$ & $28(14.9)$ & 30 (33.7) & $35(25.9)$ & $65(29.0)$ \\
\hline Sterile needle & $21(19.6)$ & $13(16.0)$ & $34(18.1)$ & $40(44.9)$ & $36(26.7)$ & $76(33.9)$ \\
\hline Can not be prevented & $1(0.9)$ & - & $1(0.5)$ & - & $2(1.5)$ & $2(0.9)$ \\
\hline
\end{tabular}

Figures in parenthesis indicate percentages 
Table 5: AIDS considered dangerous: Pre- and post-camp awareness

\begin{tabular}{|c|c|c|c|c|c|c|}
\hline \multirow[t]{2}{*}{ Dangerous } & \multicolumn{3}{|c|}{ Pre-intervention awareness } & \multicolumn{3}{|c|}{ Post-intervention awareness } \\
\hline & $\begin{array}{c}\text { Male } \\
(n=107)\end{array}$ & $\begin{array}{l}\text { Female } \\
(\mathrm{n}=81)\end{array}$ & $\begin{array}{c}\text { Total } \\
(\mathrm{n}=188)\end{array}$ & $\begin{array}{c}\text { Male } \\
(n=89)\end{array}$ & $\begin{array}{l}\text { Female } \\
(\mathrm{n}=135)\end{array}$ & $\begin{array}{c}\text { Total } \\
(\mathrm{n}=224)\end{array}$ \\
\hline Considered dangerous & $104(97.1)$ & $77(98.0)$ & $181(96.2)$ & $82(92.1)$ & $122(90.4)$ & $204(91.1)$ \\
\hline No treatment available & $58(55.7)$ & $51(66.2)$ & $109(60.2)$ & $38(46.3)$ & $79(64.7)$ & $117(57.3)$ \\
\hline No vaccine available & $7(6.7)$ & $3(3.8)$ & $10(5.5)$ & $30(36.6)$ & $11(9.0)$ & $41(10.1)$ \\
\hline Patient dies & 44 (42.3) & $9(11.6)$ & $53(12.7)$ & $23(28.0)$ & $32(26.2)$ & 55 (26.9) \\
\hline AIDS spreads fast & $16(15.3)$ & $7(9.0)$ & $23(12.7)$ & $7(8.5)$ & $7(5.7)$ & $14(6.2)$ \\
\hline Lots of money required for treatment & $2(1.9)$ & - & $2(1.1)$ & $6(7.3)$ & $3(2.4)$ & $9(4.4)$ \\
\hline
\end{tabular}

Figures in parenthesis indicate percentages

for creating awareness about AIDS. Nearly half of our respondents at baseline and over four-fifth after intervention considered the mass media (TV, radio, etc.) as sources of information regarding AIDS. Camps and health workers are important contributors, but the immense effort made by them could not achieve the desired level of awareness. TVs and radios are present in almost all households and are a good, cheap and effective channel. Similar findings were reported earlier. $^{4}$

We found that knowing about HIV/AIDS did not mean that the community was aware about its various modes of transmission and the means to prevent it. Over $70 \%$ of the respondents were aware of unsafe sex/multiple sex partners as a mode of transmission but few were aware of blood transfusion and the use of nonsterile needles and syringes; even intervention left nearly half unaware about these modes. Vertical transmission as a mode was known only to a few subjects. The use of condoms and having a single partner for sex to prevent AIDS was known to $61.2 \%$ and $72.3 \%$ of the subjects respectively after the intervention phase. Sex was considered to be an important mode of transmission. NACO reports that the sexual route is responsible for $82.24 \%$ of all AIDS cases reported in India. ${ }^{2}$ Though the FHAC led to increased awareness regarding the various routes of transmission and preventive measures, yet more than two-thirds were not aware about the role of needles/syringes and safe blood. The increase in knowledge about condoms from $42 \%$ in the preintervention phase to $61.2 \%$ in the post-intervention phase is an important gain. Use of condoms by the community can lead to a remarkable decline in HIV/ AIDS and STD prevalence. Studies report a $69 \%-87 \%$ reduction in the risk of contracting STDs, including gonorrhea, chlamydial infection, trichomoniasis and HIV infection, by using condoms. ${ }^{6}$
Many studies and IEC interventions have been reported in India in different age groups and settings with a wide range of AIDS awareness levels, e.g. 13.5\% school students and $16.2 \%$ teachers had knowledge about AIDS in Calcutta, ${ }^{7} 83.3 \%-100 \%$ students were aware in Maharashtra, ${ }^{8}$ and $83 \%$ of child development project officers (ICDS) in Delhi knew about AIDS. ${ }^{9}$ Significant improvement was seen in the areas of sex and AIDS knowledge during the post-training phase in students in Pune. ${ }^{10}$

The recent National AIDS Control Policy of the Government of India aims at preventing the spread of AIDS by making people aware of its implications and providing them with the necessary tools for protecting themselves. ${ }^{11}$ The family health awareness campaign is a remarkable effort to reach the community but the momentum has to be sustained. A large section of society is poor and still lacks basic knowledge about AIDS, its spread and prevention. While a one time activity such as FHAC enhanced the knowledge in the present study, activities such as awareness campaign, IEC activities, camps, mass media, and involvement of community leaders must be consistently implemented and their achievements assessed by regular evaluation.

\section{CONCLUSION}

The present community based intervention study on AIDS awareness observed a significant gain in awareness. More sustained efforts are needed to make the community fully aware of the prevention of HIV/ AIDS.

\section{REFERENCES}

1. UNAIDS, WHO, AIDS epidemic update: December 2002. 
Geneva Joint United Nations Programme on HIV/AIDS.

2. http: www.naco.nic.in/indianscene/overv.htm; Indian scenario. accessed 15th April, 2004, updated 31st March, 2004.

3. National AIDS Control Programme: Family health awareness campaign. Operational Guide. NACO: MOH \& FW, Government of India. Dec. 1999.

4. Lal S. Building awareness on AIDS/HIV through intensive campaign on pilot basis. Ind J Comm Med 1999;24:47-9.

5. Ahmed M, Gaash B. Awareness of HIV/AIDS in a remotely located conservative district of J\&K (Kargil). Results of a community based study. Ind J Com Med 2002;27:12-8.

6. Giron CAH, Valdez AC, Trenado MQ, Salas FU, Peruga A, Avila MH. Factors associated with condom use in the male population of Mexico City. Int J STD AIDS 1999;10:112-7.

7. Chatterjee C, Baus B, Ram R, Dhas G, Sandhu Khan S, Dan A. A study on awareness of AIDS among school students and teachers of higher secondary schools in North Calcutta. Ind J Pub Health 2001;45:27-30.

8. Ganguli SK, Rekha PP, Gupta N, Charan UA. AIDS awareness among undergraduate students. Maharashtra Ind J Pub Health 2002;36:8-12.

9. Paul D, Gopalkrishanan. Knowledge regarding modes of transmission and prevention of sexually transmitted diseases including HIV/AIDS among child development project officers. Ind J Com Med 2001;26:141-4.

10. Pratinidhi AK, Gokhale RM, Karad SR. Evaluation of sex education and AIDS prevention project in secondary schools of Pune City. Ind J Com Med 2001;26:155-61.

11. National AIDS Prevention and Control Policy. MOHFW, NACO. Government of India. 